\title{
TRANSLATING THE VIOLENT CONTENT OF GRIMM BROTHERS' FAIRY TALES: AN EYE-TRACKER EXPERIMENT
}

\author{
Meagan Carter 1 \\ Samanta de Frutos García 1 \\ Alexandra López Vera 1 \\ Karina Ornelas ${ }^{1}$ \\ Aline Ferreira 1 \\ Giselle Barbosa ${ }^{1}$ \\ Daniela Guerra ${ }^{1}$ \\ 1-University of California Santa Barbara, Califórnia, Estados Unidos
}

\begin{abstract}
Eye tracking has been introduced as a tool to analyze cognitive processes of translators in recent years. Current research with eye tracker focuses on examining translation processes. As far as we know, however, this tool has not been used for detecting eye movement behaviors related to the cognitive processing of violent content in the source text (ST). As research in this area is emerging, this study aims to determine if semantic associations with violent actions or activities in the ST produces a response in the gaze behavior of the translator. This paper presents an experimental study to investigate the cognitive processes involved in the translation of three condensed versions of Grimm brothers' fairy tales. The selected texts present the range of violent content for which these tales are renowned, from more modern adaptations which remove the violent content to very explicit and graphicly violent stories. Texts were translated from Spanish (L2) into English (L1). Fixation counts and fixation duration were calculated for each participant in ten Areas of Interest (AOI) which represented challenges in translating various aspects of grammar and violence presented in these tales.
\end{abstract}

Keywords: Eye-Tracker; Trauma; Translation; Fixation; Violent Content 


\title{
TRADUZINDO O CONTEÚDO VIOLENTO DOS CONTOS DE FADAS DOS IRMÃOS GRIMM: UM EXPERIMENTO COM RASTREADOR OCULAR
}

\begin{abstract}
Resumo: O rastreamento ocular tem sido introduzido como uma ferramenta para analisar os processos cognitivos dos tradutores. Pesquisas recentes com rastremento ocular concentram-se em examinar processos de tradução. No nosso conhecimento, no entanto, tal ferramenta ainda não foi usada para detectar comportamentos de movimento ocular relacionados ao Transtorno de Estresse Pós-Traumático (TEPT) dos tradutores, já que tais estudos estão apenas emergindo. Este artigo apresenta um estudo experimental que investiga os processos cognitivos envolvidos na tradução de três versões condensadas de contos de fadas dos irmãos Grimm. Os textos selecionados apresentam conteúdos violentos pelos quais esses contos são renomados, desde adaptações mais modernas que removem o conteúdo violento a histórias com violência explícita. Os textos foram traduzidos do espanhol (L2) para o inglês (L1). Os índices de fixação e duração da fixação foram calculados para cada participante em dez Áreas de Interesse (AOI), representando desafios na tradução de vários aspectos de conteúdo gramatical e violento apresentados nesses contos.

Palavras-chave: Rastreador Ocular; TEPT; Tradução; Fixação; Conteúdo Violento
\end{abstract}

\section{Introduction}

Understanding the varying levels of cognition in Translation Studies (TS) has been proven difficult. One key crucial element in TS is the use of eye-tracking as it allows researchers to shed some light on the cognitive processes that individuals experience when translating (Kopal; Hvelplund). When a person reads a text, their eyes move back and forth across the lines of the text from one word to another and from one sentence to another. Notable actions such as stopping at certain words or constructions or even ceasing to write a certain number of times can have a direct relation 
with the level of difficulty of certain words, structures, or the text in general for the translator (Korpal). In addition, researchers can take in information about these pauses such as the amount of time that it takes for an individual to process a specific word or construction and examine the cognitive effort involved in the translation process. Attention distribution during translation can be analyzed by recording eye fixations (Dragsted). While more traditional measures for translation difficulty in a specific task $(e . g$. total time spent in a task), data from eye-tracking showed that the areas of interest might shed more light to understanding cognitive effort in a translation task (Ferreira, Schwieter, Gottardo, and Jones (C)). Furthermore, eye-tracking, as a tool for analyzing translation, allows researchers to investigate the cognitive process by not limiting them only to analyzing the quality of the final result, but the individual translator's step-by-step process (Korpal).

This paper discusses how translators handle texts with different levels of violent content when translating from Spanish (L2) into English (L1). The short literary texts selected for this study feature acts of violence, murder, rape, and abuse with the aim to analyze the subjects' reactions during the translation process. The ultimate goal is to see if the explicit content has any effect on the cognitive effort of translators and if it interferes with their translation decisions. The elements taken into consideration for this analysis are the lexical selection, the areas of eye activation on certain words and structures, fixation counts and durations.

An important focus of this paper will be on what Sandel (2015) describes as rich points. A rich point is any verbal or non-verbal expression which is particular of a certain group or culture under study defined a priori or a posteriori that does not make sense to the researcher, and requires any translation for outsiders that could be defined a priori or a posteriori (Sandel). Rich points occur when the translator encounters a puzzling moment in either the context, grammar, or style of the text. Through those points, researchers are able to troubleshoot the developing translation between cultures and languages. According to Sandel (1), "it is during the process of 
translation, when it becomes apparent that a verbal or non-verbal expression cannot be explained simple as it linked to a number of interconnected concepts, that rich points emerge."

In previous studies, rich points have been used to pinpoint words and specific moments in translation where there was a slight confusion. Moments where rich points can be apparent are incomprehension, departures from expectations, or repackaging old forms into something new, often linked with language usage (Sandel). This paper includes an analysis of rich points with the intention of understanding the translator's point of view when they find a way to bridge a word from one language to another.

The texts selected to be translated in this study are three tales written by the Grimm Brothers which are known to be blunt, absurd, comical, and tragic. The selected stories are about children and families and the way in which they reacted to the difficult conditions under which they lived. The Grimm contribution to folklore was inspired by the desire to gather tales from oral traditions of Europe and Great Britain so as to preserve their cultural heritage (Zipes). They published their first edition in the early nineteenth century and by the early twentieth century their tales were the most famous collection of folk and fairy tales in the western world. The Grimm brothers wanted to pass on the oral tales to the German people and never assumed that those tales would assume relevance in all cultures. To delve deeper into the first version of their stories, consider how the following titles have nothing to do with happy endings or fairy tales: The Hand with the Knife, How Some Children Played at Slaughtering and The Children of Famine (Zipes). These were narratives about brutal living conditions in the 19th century; they contained a rawness that was later buffered. The Grimm Brothers' stories were simplified between the first edition and the seventh and final edition. As an example of this simplification, there was an omission of a scene in Rapunzel in which she has brutal sex with the prince. Furthermore, in the first version of Snow White, Snow White's mother, not her stepmother, wants to kill her out of 
envy (Zipes). While various aspects of the original content have been censured, much of the violent content remains and is still available in modern reprintings of the texts.

The intention of this paper is to see how the bluntness and brusque qualities of these explicit texts affect translators in their work. In essence, the aim of this study is to see if explicit violent content found in Grimm's fairy tales has an effect on the cognitive effort of the translator. A central question is related to measuring the cognitive effort involved in the translation production which is the reason why pauses during typing activity, word selection, length and duration of translation will be contemplated as indicators of cognitive effort in translation.

\section{Present study}

\subsection{Methodology and participants}

Data collection took place in a laboratory in a major university in California. Sixteen $(N=63,1$ male) participants were selected from the graduate programs in Linguistics, Iberian Linguistics, and Comparative Literature, and also from the undergraduate major in Translation Studies, but 3 were excluded due to issues with the software. Age varied from 22 to 52 years old $(M=26.15)$. Participants were self-identified as being bilinguals in Spanish and English. At the beginning of the study, participants were asked to complete a language history questionnaire in order to assess more information about their language background, demographics, and translation and language experience. The responses to the language questionnaire indicated which language was the participants' L1 (language of first use; dominant language) and affirmed translation experience. For this study, the expertise of participants ranged from novice to professional. Participants expertise was defined according to their self-reported level of experience according to the following categories: less than one year, 1-2 years, 2-4 years, more 
than 4 years. Participants with less than 4 years of experience were categorized as novices while those with more than 4 years were grouped in the expert category. Seven participants reported English as their first language (L1) and six participants reported Spanish as their L2. Six $(N=7)$ participants reported having over four years of experience and $6(N=6)$ participants reported 1-2 years of experience in translation. The expertise level of the participants was an interesting aspect in order to cater for different profiles in the subjects of this study. However, it does not have to interfere with the results since all participants reported being fluent in both languages and used them on a daily basis with friends, family, and at work/university. Most participants reported having taken theoretical and practical courses on translation and/or interpreting. Classes are taught in both Spanish and English and papers, essays, and tests are written in both languages. Using a language history questionnaire, a Likert-scale $(1-5,1=$ not fluent and 5= very proficient) was used to analyze their English and Spanish reading, speaking, and listening proficiency:

Table 1: self-reporting proficiency in English and Spanish (from 1 to 5$)^{1}$

\begin{tabular}{|c|c|c|c|c|c|c|c|}
\hline $\begin{array}{l}\text { English } \\
\text { Reading } \\
\text { Proficiency }\end{array}$ & $\begin{array}{l}\text { English } \\
\text { Speaking } \\
\text { Proficiency }\end{array}$ & $\begin{array}{l}\text { English } \\
\text { Listening } \\
\text { Proficiency }\end{array}$ & $\begin{array}{l}\text { English } \\
\text { Writing } \\
\text { Proficiency }\end{array}$ & $\begin{array}{l}\text { Spanish } \\
\text { Reading } \\
\text { Proficiency }\end{array}$ & $\begin{array}{l}\text { Spanish } \\
\text { Speaking } \\
\text { Proficiency }\end{array}$ & $\begin{array}{l}\text { Spanish } \\
\text { Listening } \\
\text { Proficiency }\end{array}$ & $\begin{array}{l}\text { Spanish } \\
\text { Writing } \\
\text { Proficiency }\end{array}$ \\
\hline 4.5 & 4.43 & 4.43 & 4.2 & 4 & 3.93 & 4.31 & 3.5 \\
\hline
\end{tabular}

Participants were also asked to complete a series of tasks which included translations of three condensed texts, retrospective think-aloud protocol, and a psychological diagnostic survey. As per information from the self-reporting translation experience evaluation survey, participants have been categorized into two

\footnotetext{
1 The tables and figures featured in this paper were generated using the data collected for this study by the researchers and the UCSB Bilingualism, Translation, and Cognition Laboratory.
}

Cad. Trad., Florianópolis, v. 40, n⿳ 1, p. 17-33, jan-abr, 2020. 
groups: professionals and novices. For the purpose of this study a professional was determined to be a participant who has more than four years of translation experience, where experience is defined as the activity in which that person has been researching and, therefore, receiving her income from. On the other hand, novices are participants who have less than four years of translation experience, resulting in six professionals and seven novices in the sample. In previous studies on experience, a professional criteria served as the basis for determining novice and expert status (see Katan and Hunziker Heeb for more information on the expertise and translation debate). However, as only a very limited number of participants reported having any professional experience, this study will aim to examine differences in cognitive processes across the two levels of self-reported formal and informal translation experience of bilinguals.

After completing the questionnaire, participants translated three texts from Spanish to English. The source texts were in Spanish to account for how participants' L1 and the L2 language may influence the directionality of the translation tasks. All participants reported English as their L1. Seven participants reported being exposed to Spanish since birth at home but having received most of their schooling in English. It is important to consider their language dominance as translators face fewer lexical problems and have access to more options on how to solve problems presented when translating into their L1 in comparison to their L2 translation, where they face more lexical problems and there are fewer options to solve the problem. The problems presented during L2 may be accounted for by the asymmetric relationship in how L1 and L2 words are mapped in bilingual memory (Ferreira (a), (b)).

The translation tasks were recorded using Tobii T60 and Tobii Pro Studio, an eye tracking machine and software that calculates the eye movements of a participant across a computer screen. Each participant's keystrokes were recorded via Translog-II software. The source texts were presented through Translog-II and were divided into two parts per text due to formatting constraints of 
the software, which resulted in a total of six Translog texts per participant (2 Translog screens per fairy tale). The computer screen was split into two sections throughout the duration of the translation tasks; on the left half of the screen was Translog and on the right half was a web browser. The web browser had three tabs open to Google Translate, Word Reference, and Linguee, available as external support for the use of the participants. Participants also had the option to search for additional information outside of these resources. The data attained through Tobii Pro Studio and Translog will provide insight on how participants resolved problems in translating various grammatical and lexical considerations regarding the violent content of the text.

The texts were consciously selected a priori with the aim of presenting extracts with violent content that could serve as a stimulus by which to analyze how bilingual students of translation react to the violent content of STs. The participants were required to translate the texts in order to ensure that the participants would be exposed to the content of the STs and not scan them. Having the participants simply read the text would not have been effective due to the possibility that they might not fully engage with its content. The translation task ensures enough engagement with the text since it requires source-text comprehension in one language, and target-text production in another language (Jakobsen (b)). Just as important is that the translators processing knowledge may be manifested into translational behavior and allows for the study of cognitive processes during the translation task.

The source texts consisted of three popular Grimm's tales Cinderella, The Three Snake-Leaves, and The Robber Bridegroom. The tales were selected due to their well-known controversial thematic violent content, such as kidnapping, rape, and murder. Spanish translations of the tales were retrieved from the website Grimm Stories and were condensed to ensure a similar level of text complexity as measured in word count: 159, 158, and 155 words respectively. The source texts were presented in order of increasing thematic content, with the first Source Text (ST) presenting the 
least amount of violent content and the final ST containing the most violent content. The violent content of the source texts ranged from low, moderate, to high. The level of violent content was categorized by how many instances of violence were present in the ST. More particularly, the focus was on moments with more graphic scenes which include terminology referring to instances of murder, rape, drug and abuse. An analysis was made in different fairy tales and the graphic instances were counted. Cenicienta served as the control text due to its wide popularity in the United States and its general lack of violent content. The second source text, The Three Snake-Leaves, had a moderate level of violent content seeing that it only contained two instances of violence. The final source text, The Robber Bridegroom had four instances of violence and therefore was labeled as having a high amount of violent content. A description of the instances is presented in section 3 .

A retrospective think-aloud protocol (RTA) interview was conducted at the end of the translation tasks. The RTA was used to obtain more information about the translation task without increasing the cognitive load on the participant as it does not interfere with the level of cognitive effort observed in the tasks (Tirkkonen-Condit). Participants were shown a replay of the translation in Tobii Studios and were asked to comment on the difficulties they encountered and their decision-making progress. Viewing the recording, the researchers tried to recover as much information as possible from the translator about their cognitive behaviour and asking for clarification about their decision-making processes. Thus, the completion of a RTA in the investigation allowed for reflections on translation of a more subjective nature (Jakobsen (a)).

Following the RTA, participants completed the PostTraumatic Stress Disorder Checklist for DSM-5 (PCL-5). The physical diagnostic survey was attained through the United States Department of Veteran Affairs website in conjunction with the National Center for PTSD. The purpose of the PCL-5 was to account for external experiences in the translators' lives in the month prior to the translation and to control for PTSD as a factor. 
It was hypothesized that meeting the criteria for a provisional diagnosis of PTSD could significantly alter the cognitive reactions of the translators to the extent that this group of participants would focus more on the violent content than those who did not meet the criteria for a provisional diagnosis. Thus, the survey served the purpose of screening participants with PTSD and examining how participants experience in the month prior to the translation may have influenced their response to the ST.

Four professionals and three novices met the DSM-5 provisional diagnostic criteria for provisional PTSD, according to the diagnostic survey. An official diagnosis of PTSD cannot be assigned any participant in this study due to the fact that the PCL-5 is not intended to serve as an independent diagnostic tool of PTSD. Rather, its purpose is to quantify and monitor symptoms over time, screening individuals for PTSD, and assisting in making a provisional diagnosis of PTSD (National Center for PTSD, 2018). The survey consisted of the 20 items listed for the PTSD checklist for DSM-5 in which participants had to select how impacted they had been by the items listed ranging from a 0 to 4 scale. There are two methods in which the PCL-5 can be used to determine a provisional diagnosis; however due to its direct correspondence to the DSM-5 criteria for PTSD, only the first method was utilized for determining a provisional diagnosis for this study. In this method, every item rated as 2 or higher on the survey is treated as an endorsed symptom. This method requires that the following items be rated as 2 or higher: one item pertaining to questions 1-5, one item from questions 6-7, 2 items from questions 8-14, and 2 more items from questions 1520. Participants who met these criteria were assigned a provisional diagnosis of PTSD on the basis that according to the DSM-5, these participants may benefit from receiving treatment.

\section{Analysis and Results}

Ten areas of interest (AOI) were selected across two 
categories representing two distinct types of translation issues: grammar and violence. Five AOIs were chosen a priori that were anticipated to present a grammatical translation challenge to the participants: "Érase una hijita huérfana," "corrió," "eligiese," "A continuación," and "viniera." "Érase una hijita huérfana" and "A continuación" were chosen as connectors, which would present the participants with the difficulty of changing grammatical categories and syntactic structures from Spanish to English. Additionally, they appear at the beginning of their respective texts. Therefore, these two connectors will be analyzed in the present study, and he remaining three AOIs for grammar reflect problems in translating the past indicative and imperfect subjunctive from Spanish into the English past tense.

Five AOIs were also selected which represented violent content from the STs: "le echó," "herida," "le arrancaron," "cortaron," and "en pedazos". The latter four were selected a priori as each one depicted a moment of character to character violence in the forms of physical wounding with a sword, gang rape, and murder. For those reasons, "herida" was labeled as a moderate-level of violent content whereas "le arrancaron," "cortaron," and "en pedazos" were labeled as high-level violent content. "Le echó," on the other hand, was selected a posteriori after reviewing the RTAs. This AOI appears in the Cenicienta text when the bird, who in modern versions is portrayed as the fairy godmother, gives Cenicienta the dress to go the ball and dance with the prince. However, multiple participants reported in the RTAs having read this moment in the ST not as "the bird gave her a dress" but rather as "the bird threw a dress at her." In order to gauge the cognitive impact of this perception of violence in the ST, "le echó" was added to the AOIs for violent content and assigned as low-level violent content.

Eye tracker data was collected for each participant and AOI. Prior to analysis, each AOI was verified using eye tracker heat map gaze data to ensure that these were areas which presented difficulties to the participants. Each AOI was analyzed for fixation duration and fixation count. The mean total fixation duration for 
the areas of interest are listed in Figure 1 and the fixation counts per AOI are found in Figure 2:

Figure 1: Mean Total Fixation Duration (Areas of Interest)

Mean Total Fixation Duration per Area of Interest

6000

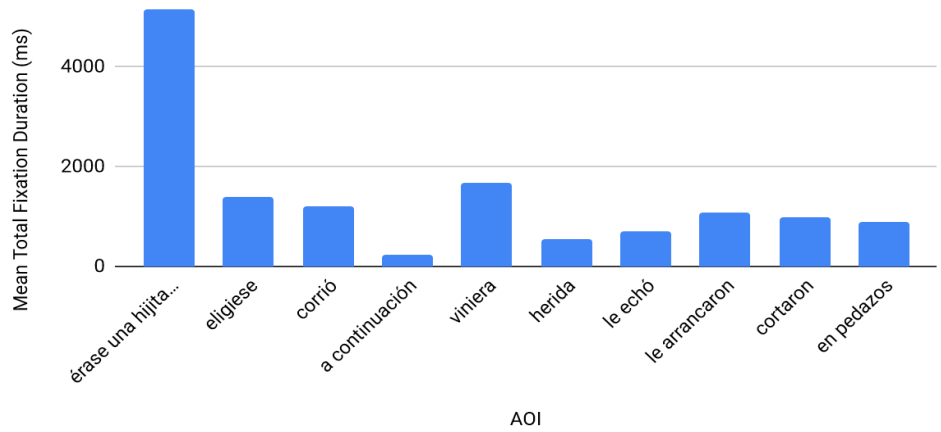

Figure 2: Mean Fixation Count (Areas of Interest)

Mean Fixation Count per Area of Interest

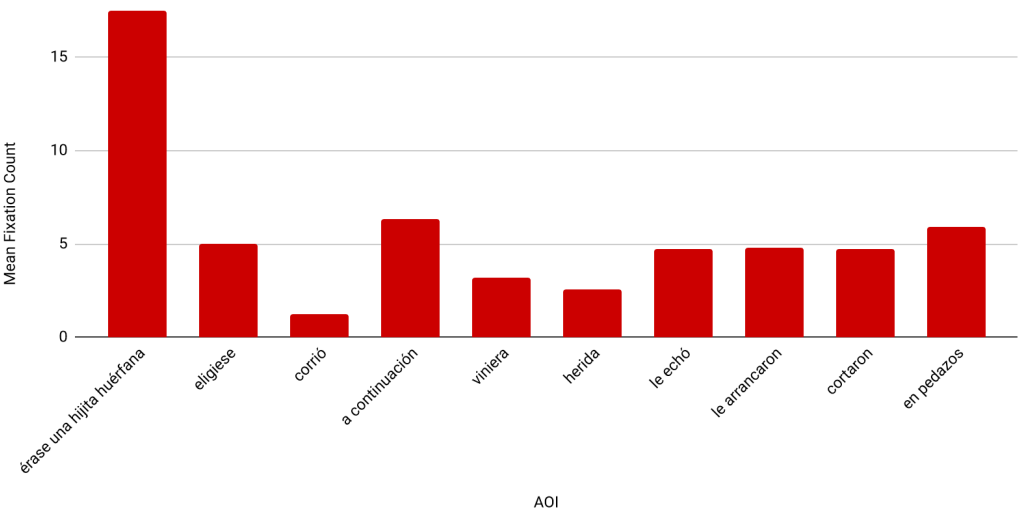

Cad. Trad., Florianópolis, v. 40, $\mathbf{n}^{0}$ 1, p. 17-33, jan-abr, 2020. 
The results from both graphs support that the participants gaze more frequently at the first constituent in the ST. Participants gazed considerably more often and for a longer mean fixation duration at "érase una hijita huérfana" than any of the AOIs. This was partially reflected in "a continuación" for which the mean fixation count was only slightly higher than "en pedazos". However, the participants spent the least amount of time in this AOI. In order to test for the significance of the differences between the two main categories of translation problems, grammar and violent content, an analysis of variance was performed and p-values were obtained.

The results from the ANOVA test showed that relative experience and the PCL-5 provisional diagnosis were not significantly related to the fixation counts and the mean total fixation durations for these AOI. Results showed no significant correlation between experience or provisional PTSD status and fixation duration. However, it is important to note that the PCL-5, used for determining provisional PTSD status, p-value is 0.0666 . Nevertheless, this means that for this set of participants, the level of experience and their provisional PTSD diagnosis were not factors that affected the length or number of times they fixated on the areas of interest.

Two factors did prove to be significant in their impact on fixation counts and mean total fixation durations. The relationships between AOI and fixation proved to be highly significant in terms of fixation count $(\mathrm{p}=3.94 \mathrm{e}-10)$ and mean total fixation duration $(\mathrm{p}=2.69 \mathrm{e}-10)$. In order to gain more insight as to the nature of the relationship between AOI type and fixation, a pairwise t-test was performed on both AOI categories, grammar constructions and violent content, and fixation. For the fixation count, the factors of grammatical constructions and violent content did not have a significant $\mathrm{p}$-value $(\mathrm{p}=0.075)$. Therefore, the $\mathrm{p}$-value from the ANOVA test could reflect differences between the individual AOIs that are independent of the current classification of grammar construction and violent content. More research with various types of AOIs representing other types of translation issues is 
needed in order to determine the exact relationship between AOI categorization and mean fixation count.

The relationship between mean total fixation duration and AOI category did prove highly significant with the pairwise t-test $(\mathrm{p}=0.014)$. The mean total fixation duration for grammatical constructions was 1935 milliseconds while the mean total fixation duration for violent content was 845 milliseconds. Participants fixated on the AOIs for grammatical constructions almost twice as long as for the AOIs for violent content. In terms of mean total fixation duration, grammar and violent content were factors that affected whether the participants fixated on words for longer or shorter amounts of time. For the participants, grammatical constructions have presented more of a translation challenge than the violent content of the ST.

\section{Conclusion and Future Studies}

Results discussed here are part of a project that has been conducted to investigate the relationship amongst bilingual translation experience, L2 to L1 translation, and source text content. This project could be expanded in many ways. First of all, the sample size could be enlarged in order to include a broader and more diverse population; this could include an increased number of participants in addition to people from different backgrounds, genders, and experience levels. This change would enrich the results. Another revision that could enhance the population's credibility involves surveys. Surveys that clearly emphasize participant's professional translation experience could be supplemented by a baseline exam that all participants must take to determine expertise. Included with this could be a questionnaire asking for previous professional translation experience; this could include coursework, previous jobs, internships or previous translation opportunities. Conducting other related studies could also aid in legitimizing data. For example, studies on fatigue and how this affects participant translation could 
be a useful tool; this could include trial runs with a smaller word count in each window and less texts to translate. English correlated source texts will be added to this experiment to investigate whether the same participants will present longer fixations in specific rich points when translating into Spanish.

In order to further analyze the data derived from this experiment, future studies could involve saccades and how they affect fixation time. Additionally, studies analyzing the relationship between the target text, the participant's language and translation experience, and PCL-5 provisional diagnosis could further examine the relationship between violent content, PTSD, and translation. As researchers continue to analyze PTSD in literature, more studies should be conducted to help us to better develop empirical studies that challenge the traditional concept of trauma as unspeakable. There are a variety of approaches to studying trauma in literature, and this research will be further developed to contribute to a better comprehension of translation process and trauma. While this study may not be used as a generalized illustration of the target population, it does serve as a prototype for further research opportunities, which can involve relationships between amount and duration of fixations in relation to grammar and violent content.

\section{References}

Carandini, M. "Visual cortex: Fatigue and adaptation". Current Biology, [s.1], 10.16 (2000): 605-607.

Ferreira, A. Direcionalidade em tradução: uma investigação do processamento cognitivo de tradutores profissionais em tradução direta e inversa no par linguístico inglês-português. Dissertação (Mestrado em Linguística Aplicada) - Faculdade de Letras, Universidade Federal de Minas Gerais, Belo Horizonte, 2010(a).

Cad. Trad., Florianópolis, v. 40, n⿳0 1, p. 17-33, jan-abr, 2020. 
Ferreira, A. "Analyzing recursiveness patterns and retrospective protocols of professional translators in L1 and L2 translation tasks.". The Development of Professional Competence Translation and Interpreting Studies. The Journal of the American Translation and Interpreting Studies Association Translation and Interpreting Studies. [s.1], 9.1 (2014(b)): 109-127.

Ferreira, A., Schwieter, J. W., Gottardo, A., and Jones, J. "Cognitive effort in direct and inverse translation performance: Insight from eye-tracking technology." Cadernos de tradução, Florianópolis, 36, 3 (2016(c)): 60-80. Disponível em: http:// www.scielo.br/scielo.php?pid $=$ S2175-79682016000300060\&script $=$ sci_abstract.

Grimm, J. H. (n.d.). "La Cenicienta Cuento". Retrieved from https://www. grimmstories.com/es/grimm_cuentos/la_cenicienta.

Grimm, J. H. (n.d.). “The Three Snake Leaves”. Retrieved from https://www. grimmstories.com/language.php?grimm $=016 \& l=e n \& r=e s$.

Grimm, J. H. (n.d.). “The Robber Bridegroom”. Retrieved from https://www. grimmstories.com/language. php? grimm $=040 \& l=e n \& r=e s$.

Hunziker-Heeb, A. "The problem-solving processes of experienced and nonexperienced translators”. In: Kersten, S.; Ludwig, C.; Meer, D.; Rüschoff, B. Papers selected from the Junior Research Meeting. Language learning and language use - applied linguistics approaches. Duisburg: UVRR (2012): 177-186.

Hvelplund, K. T. "Eye Tracking in Translation Process Research. The Handbook of Translation and Cognition", edited by John W. Schwieter and Aline Ferreira, Wiley Blackwell Press, 2017: 548-264.

Jakobsen, A. L. "Effects of think aloud on translation speed, revision, and segmentation". Triangulating Translation. Perspectives in Process Oriented Research, edited by Fabio Alves, (2003): 69-95. Amsterdam: John Benjamins, (a)

Jakobsen, A. L. "Investigating expert translators' processing knowledge". Knowledge Systems and Translation (2005):173-189.

Katan, D. "Translation Theory and Professional Practice: A Global Survey of the Great Divide". HERMES - Journal of Language and Communication in Business, [s.1], 22.42 (2017): 111-153. 
Korpal, P. "Eye-tracking in Translation and Interpreting Studies: The growing popularity and methodological problems" (2015). https://www.researchgate.net/ publication/297484787_Eye-tracking_in_Translation_and_Interpreting_Studies The_growing_popularity_and_methodological_problems.

PTSD: National Center for PTSD. (2018, September 24). Retrieved from https:// www.ptsd.va.gov/professional/assessment/adult-sr/ptsd-checklist.asp.

Sandel, T. "Rich Points". The International Encyclopedia of Language and Social Interaction, edited by Karen Tracy, Cornelia Ilie, and Todd Sandel . (2015). Wiley-Blackwell: Malden, MA.

Swender, E., Martin, C.;, Rivera-Martinez, M., Kagan, O. E. "Exploring Oral Proficiency Profiles of Heritage Speakers of Russian and Spanish". Foreign Language Annals, [s.1], 47.3 (2014): 423-446.

Tirkkonen-Condit, S. “Think-Aloud Protocols”. Brown, K. Encyclopedia of Language \& Linguistics. 1 (2006): 678-86.

Zipes, J. "How the Grimm Brothers Saved the Fairy Tale". (2015). Retrieved February 23, 2019 from https://www.neh.gov/humanities/2015/marchapril/ feature/how-the-grimm-Brothers-saved-the-fairy-tale.

Recebido em: 05/09/2019

Aceito em: 27/12/2019

Publicado em janeiro de 2020

Meagan Carter. E-mail: meagancarter@ucsb.edu.

ORCID: https://orcid.org/0000-0003-4602-5556

Samanta de Frutos García.E-mail: samanta@ucsb.edu

ORCID: https://orcid.org/0000-0002-6447-4825

Alexandra López Vera.E-mail: lopezvera@ucsb.edu

ORCID: https://orcid.org/0000-0001-76593672

Karina Ornelas.E-mail: ornelask97@gmail.com

ORCID: https://orcid.org/0000-0001-5517-2828

Aline Ferreira: E-mail: alineafe@gmail.com

ORCID: https://orcid.org/0000-0002-2906-7343

Giselle Barbosa.E-mail: gisellebarbosa@umail.ucsb.edu

ORCID: https://orcid.org/0000-0002-1283-7030

Daniela Guerra.E-mail: danielaguerra@umail.ucsb.edu

ORCID: https://orcid.org/0000-0002-2641-9374 